\title{
Hacia Cortázar, a Partir de Borges
}

Nada de lo que es deberá ser substraido, nada es dispensable. (Nietzsche: Ecce Homo).

En "La postulación de la realidad" (1931), Borges resume la discreta economía narrativa del escritor clásico. Sin entrar en detalles, conviene ahora destacar la diferencia fundamental que según Borges distingue el proceder clásico del romántico: mientras que el segundo intenta representar la realidad, el primero se limita a registrarla. No cabe duda que el Borges cuentista se adhiere a la primera de estas dos estrategias, y que la "simplificación conceptual de estados complejos" señalada por él en el mismo ensayo, anticipa lo que enunciará un año más tarde al final de "El arte narrativo y la magia". La simulación psicológica intenta, vanamente, plasmar las "incontrolables e infinitas operaciones" propias de la causalidad natural; frente a esta tentativa (atribuible al escritor romántico) el clásico ejercitará la narración en plena y sabia conciencia de la "notoria ineficacia" de las mediaciones textuales. Las deliberadas omisiones admitidas por este tipo de escritura o de aproximación a la realidad se deberán articular con los pormenores proféticos; el texto será lo esencialmente necesario, pero esta fascinante autosuficiencia del texto propiciará un infinito número de lecturas.

La dialéctica propuesta por Borges revela la ineficacia de toda postulación empírica que se proponga acentuar la fidelidad de nuestros procesos imaginativos con relación a los textos. Por su parte, el novelista y profesor de filosofía norteamericano William $\mathrm{H}$. Gass, llega, con algún retraso, a la conclusión que "our imaginings are mostly imprecise". En el mismo ensayo ("The Concept of Character in Fiction", Fiction and the Figures of Life, p. 41) cita a Hume como el exponente clasico de la fe empiricista. Reproduzco parte de la cita: "The imagination has the command over all its ideas and can join and mix and vary them in all 
the ways possible. It may conceive fictitious objects with all the circumstances of place and time. It may set them in a manner before our eyes, in their true colors, just as they might have existed". De entre las conclusiones a que llega Gass, después de considerar el texto de Hume, cabe aislar la siguiente: "Only a few of the words which a writer normally uses to create a character can be 'imaged' in any sense"; más su corolario epigramático: "On the other side of a novel lies the void". (Pp. $47 \mathrm{y}$ 49). Io dicho aquí repite, con mayor denuedo retórico y con otros fines, algunos de los conceptos expuestos por Borges en " $\mathrm{La}$ postulación de la realidad". Pero, mientras que Gass se sitúa momentáneamente dentro de la expectativa del lector, para reajustarla, Borges, en lo citado a continuación, va más lejos. Lo que hace es trazar el límite más radical de nuestra atención desde la perspectiva del escritor que admitirá dicho limite en su obra, pero solo para aprovecharse de él y extender el alcance de ésta: "Nuestro vivir, dice Borges, es una serie de adaptaciones, vale decir, una educación del olvido. Es admirable que la primera noticia de Utopía que nos dé Thomas More, sea su perpleja ignorancia de la 'verdadera' longitud de uno de sus puentes..." (Discusión, quinta impresión, p. 70). La negación, como en Hegel, introduce lo que deberá ser afirmado: el vasto conocimiento que posee More sobre Utopía se impone ( $y$ con él la verosimilitud del objeto que pretende conocer) al insertarse en el hilo de la narración el desconocimiento de un dato en particular. La ausencia es el punto ciego a través del cual se expanden el universo de lo narrado y los entes que lo habitan. Mientras más concentrada sea la expresión de dicha ausencia, más fuerte y expansivo será el deseo de cubrirla. El "recuerdo limitado y menguante de Herbert Ashe" que, en "Tlön, Uqbar, Orbis Tertius", persiste "en el hotel de Adrogué", confiere a la ausencia del personaje (a su inalcanzable permanencia) un carácter astral.

El fenómeno de la ausencia permite comparar este pasaje de "Tlön, Uqbar, Orbis Tertius" con el texto de Gibbon comentado en "La postulación de la realidad". La escritura de Gibbon es, según Borges, "generalizadora y abstracta hasta lo invisible". El historiador asume la narración a partir del reinado del silencio, después de la batalla y de la partida de los Godos. Tanto en el cuento como en la narración histórica, la escritura se compone de póstumas alusiones. Lo que la define es la mesurada incantación de una ausencia.

De esta manera Borges insiste en la textualidad (algunos dirian $l i$ teralidad) de la narrativa, situándola en constante juego dialéctico con el deseo de ver más allá del texto, de profundizar en él, de descubrir 
la interioridad en que se alojan las psicologias, las presencias y todo aquello que promueva la vieja necesidad del humanismo por la esencia. Ahora bien, sus más empecinados lectores saben que más allá del texto, y contrario a lo dicho por Gass, no está el vacío (the void) sino la posibilidad de otros textos. Pero en cuentos como "El Sur" las peripecias del protagonista realzan la persistente ilusión de que en lo leido se mueve por lo menos una vida, en el sentido más común del vocablo. Es decir, al final de sus cuentos todo queda asimilado dentro de las posibles mediaciones textuales, pero en "El Sur", donde lo que se narra es precisamente cierto ingreso en la ficción, cierta textualización, el lector debe imaginar el tránsito de la vida a la ficción, de lo contingente a las coordenadas del texto, y todo con la ambivalencia del que ve ante el personaje ( $y$ a través de éste ante sí mismo) una prisión y una muerte, pero también la consumación privilegiada de su destino, del Amor Fati exaltado por Nietzsche.

Escojo "El Sur" de paso hacia Cortázar, o hacia cuatro de sus cuentos, como el paradigma de un hecho muy repetido en su ficción. Partiendo de "Continuidad de los parques" y cerrando con "Casa tomada", "Carta a una señorita en París" y "Cefalea", me intèresa explorar, más que el ingreso en la ficción, la caída en ésta, el encontrarse súbitamente atrapado en ella, o en algo que le sea análogo como fin definitivo de un traslado ontológico. Caída o viraje al que se asemeja el vivir regido por ciertos textos, por la inminencia de un orden que disuelve la subjetividad. ${ }^{1}$

\section{II}

"... ansiedad que nacia de una ma.
nera de estar metido en el juego, de
estar preso en el juego, de estar de en-
trada en juego dentro del juego."

Jacques Derrida.

2 La crítica ya se ha aproximado a Cortázar por esta via, pero con resultados no del todo satisfactorios. El esíuerzo más acertado parece ser el de Lanin A. Gyurko, "Hallucination and Nightmate in Two Stories by Cortazar", Modern Language Review, July 1972, pp. 550-62. En lo sucesivo se citará por: Jorge Luis Borges, Discusión, quinta impresión, Buenos Aires, 1969; Ficciones, decimotercera impresión, Buenos Aires, 1971; y Julio Cortázar, Bestiario, sexta ediciôn, Buenos Aires, 1967; Final del juego, segunda edición, Buenos Aires, 1964. 
El destino que rige la vida de Juan Dahlmann se resume en "la discordia de sus dos linajes", y en la elección desde joven de "una muerte romántica". El ser de sus antepasados detenta los signos que acabarán por configurar el futuro del personaje, transformando la idea de elegir una muerte en la de consumar un pasado. Los resortes de esta dialéctica pueden ser localizados en la materialidad de las cosas y en la transfiguración de éstas en estados cada vez más indefinidos y abstractos, pero no menos presentes en la conciencia del protagonista. La jerarquía que conduce de lo material a lo abstracto es dada en el primer párrafo del cuento. En lo sucesivo las cosas y los estados del alma, lo inette y el devenir, se fundirán inexorablemente: "Un estuche con el daguerrotipo de un hombre inexpresivo y barbado, una vieja espada, la dicha y el coraje de ciertas músicas, el hábito de estrofas del Martin Fierro, los años; el desgarro y la soledad, fomentaron ese criollismo algo voluntarioso, pero nunca ostentoso." (Ficciones, pág. 187). El orden riguroso de esta relación parte de la materialidad (estuche, espada) y culmina en estados indefinidos y amplios (desgarro, soledad). Orden articulado por el tiempo, y tiempo que se manifiesta en progresivos distanciamientos, en ausencias de seres $y$ de cosas. La materialidad se disuelve $y$ transforma por su adjetivación en el tiempo ("la larga casa rosada que alguna vez fue carmesi"; "El almacén, alguna vez, había sido punzó, pero los años habían mitigado para su bien ese color violento") hasta alcanzar el grado de lo cósmico: "Ya el blanco sol intolerable de las doce del día era el sol amarillo que precede al anochecer y no tardaría en ser rojo" (p. 191).

"El Sur" narra el regreso a las cosas o, mejor, el regreso de éstas. Al comienzo del cuento Dahlmann vive en la dispersión, su trayectoria será hacia la pura concreción, la de sumarse a los textos, a las figuras que le han aguardado desde siempre en el Sur, zona de las ficciones más determinantes dentro de la mitología del país. Cuando Dahlmann sale del sanatorio, por la simetría del sueño o de lo real, las cosas regresan a él. No las ve, las recuerda, y reconoce la ciudad "unos segundos antes" de que la registren sus ojos. El verbo empleado en "La postulación de la realidad" para definir aquella escritura "generalizadora y abstracta hasta lo invisible", delata que el personaje ya es parte de una lectura, de $s u$ lectura. Pero entre él y las cosas se ha teafirmado un lapso de algunos segundos, lapso éste propio de la intencionalidad de la conciencia del que existe. El ingreso en la ficción no se consumará hasta que Dahlmann no se rcina con su negativo ficticio en la eterna instan- 
taneidad de su configuración textual, donde la voluntad y el acto son simultáneos.

Las simetrías y las discordias inscritas en "El Sur", sobre la marcha hacia la muerte prometida, requieren un desenlace que ningún texto puede efectuar, pero si aproximar: imagínese el relato desplegado sobre una lámina la cual, al ser doblada por su centro haría coincidir, término por término, los signos contenidos en sus dos mitades ahora superpuestas en perfecto encaje. ${ }^{2}$ Tanto el habitual ascensor que Dahlmann descarta, como la accidental escalera que ocasiona la herida coincidirian, respectivamente, con "la estación de siempre", a la que esta vez no llega, y con la "otra, un poco anterior y apenas conocida" (Ficciones, p. 192). Como igualmente lo harían la "arista del batiente" (que "le rozó la frente") con "el leve roce en la cara" que siente en el almacén a causa de "la bolita de miga" y, finalmente, con el puñal que esgrimirá momentos después. El "odio a su identidad", sentido en el sanatorio, sería complementado por su cara ("accidental") frente a los gauchos del almacén, y por el acto de asumir la obligación que le impone su nombre al ser éste pronunciado por el patrón.

La convergencia simétrica de las dos mitades hace estéril el tratar de distinguir si Dahlmann experimenta o no una pesadilla, ya que "El Sur" lleva a su conclusión ontológica el conocido principio de que los sueños repiten y modifican datos y estímulos recientes. En fin, el cuento rebasa los límites de lo psicológico.

Quedan por explorar en este breve encuentro con "El Sur" los pasos finales de ese ingreso en la ficción que convierte a Dahlmann en personaje de sí mismo, en ficción de una ficción.

Dos presencias en "El Sur" definen este proceso. Ia primera sería la del "enorme gato" que se deja acariciar por la gente "como una divinidad desdeñosa". Dahlmann lo acaricia, antes de abordar el tren, pero el gesto no anula la inapelable ausencia del animal. Ambos están "como separados por un cristal", ya que "el hombre vive en el tiempo, en la sucesión, y el mágico animal, en la actualidad, en la eternidad del instante" (Ficciones, p. 190). La ausente y desdeñosa presencia del gato anticipa otra más definitiva, $y$ que pertenece a un orden análogo

2 Ya esta imagen fue sugerida por Ronald J. Christ en su The Narrow Act (New Yotk 1969), p. 125. En lo que sigue tomo en cuenta lo dicho por Borges a James Irby: "Everything that happens after Dahimann leaves the sanatorium can be interpreted as an hallucination of his at the moment of dying from septicemia, as a fantastic vision of how he would have wanted to die", citado por Christ, Ibid., p. 125. Según el presente enfoque, lo importante es la asimilación del primer plano por el segundo a nivel ontológico, ya que el texto mismo cancela el hiato. 
en la escala de lo inmutable: la del viejo gaucho (sin duda epifanía de Martín Fierro). La descripción de este último sella la analogía:

En el suelo, apoyado en el mostrador, se acurrucaba, inmóvil como una cosa, un hombre muy viejo. Los muchos años lo habían reducido y pulido como las aguas a una piedra o las generaciones de los hombres a una sentencia. Era oscuro, chico y reseco, y estaba como fuera del tiempo, en una eternidad. (Ficciones, p. 193).

El gato y el gaucho pertenecen, contrario a las demás cosas de "El Sur", a la categoría de lo que no cambia. Son cosas, pero su reificación, que en el mundo cotidiano equivaldría a una especie de muerte, es aquí em: blema del puro ser-en-sí de los entes de la ficción, ser que se escapa a toda lectura. Porque la lectura será siempre víctima de la accidentada sucesión que constituye el tener que efectuarla ent el tiempo. El Borges lector de Appearance and Reality sabe que toda lectura confirma, sin proponérselo, lo que F. H. Bradley llamaba con desdén la pura o desnuda conjunción (bare conjunction), y que el idealismo del filósofo suponía como única proposición verdadera la que lo dijera todo simultáneamente. Por eso, cuando Dahlmann atraviesa el umbral y "empuña con firmeza el cuchillo, que acaso no sabrá manejar", ingresa en un orden más allá de toda lectura. Como al gato, lo separa de los hombres un cristal, el texto que lo multiplicará a partir de su eterna condición de ser lo mismo.

La lectura de "El Sur" como paradigma permite ahora una aproximación más cabal a Cortázar, mediante cuatro de sus cuentos. El ingreso en la ficción se convierte en súbito traslado ontológico. "Continuidad de los parques", que a primera vista no es más que una leve parábola sobre los peligros de la lectura efectuada desde el ámbito burgués, contiene elementos de mayor alcance, los cuales convergen hacia un desenlace paralelo al estudiado en "El Sur", aunque en clave diferente.

El texto del melodrama que atrapará al hombre de negocios sacándolo de su cómoda lectura es, al principio del breve relato, algo inerte. Posee la pura materialidad de "novela" o de "libro", objetos que podrán ser abiertos ("volvió a abrirla cuando regresaba en tren") o abandonados ("La abandonó por negocios urgentes"); objetos siempre a la disposición de la voluntad del que lee ("volvió al libro en la tranquilidad del estudio"). Dicha inercia incluye sitios que más adelante se convertirán en agentes al ser absorbidos por el texto. La primera mención del parque lo revela como el objeto pasivo de la perspectiva cen- 
trada en el estudio ("volvió al libro en la tranquilidad del estudio que miraba hacia el parque de los robles"); pero en la segunda su inercia de puro telón de fondo ha sido eliminada por el movimiento ("más allá de los ventanales danzaba el aire del atardecer bajo los robles"). El espacio reificado de la lectura escapista es invadido paso a paso por el espacio intencional, el de la continuidad y las posibilidades. El nexo que une la primera mención del parque con la segunda es la puerta del estudio, análoga al "libro", pero al libro ya transformado en sitio de una posible acción: "Arrellenado en su sillón favorito, de espaldas a la puerta que lo hubiera molestado como una irritante posibilidad de intrusiones". (Final del juego, p. 9). El lector se va entregando a la voluntad del texto, "dejándose ir". hacia un texto cada vez más inten. cionado ("dejándose ir hacia las imágenes que se concertaban"). Los lugares comunes atribuidos a la novela ("el dibujo de los personajes") son asimilados por el texto y regresan al lector con fatal intención: "Hasta las caricias que enredaban el cuerpo del amante como queriendo retenerlo $y$ disuadirlo, dibujaban abominablemente la figura de otro cuerpo que era necesario destruir" (Final de juego, P. 10). El desenlace del relato fundirá la rigidez de la vieja trama del adulterio con la serie de repeticiones cotidianas que es la vida del negociante, distribuida en horas y lugares prescritos.

Mientras que Dahlmann se inserta en la épica de su país a través de uno de los anónimos y constantes incidentes que ilusoriamente la reviven, lo que sucede al negociante lector es, a nivel ontológico, de indole muy distinta. El texto leído en "Continuidad de los parques" se apodera de una vida vacía, distinta a la de Dahlmann, puesto que aquélla, aunque dispersa, contenia en "las costumbres de su memoria" la posibilidad de configurarse un destino. El personaje de Cortázar es el descendiente paródico de esas figuras de la narrativa moderna que, según René Girard, (en Mensonge Romantique et Vérité Romanesque) tienen que aprender a desear copiando el deseo inscrito en los textos. Especie de Narciso sin otra figura que la del reflejo de su propia vacuidad.

III

Ya en Bestiario (1951), Cortázar había reunido en un número reducido de precisas narraciones varias de las facetas de la enajenación. Antes de examinar "Cefalea", como otro episodio más del imperio de 
los textos, consideraré las variantes del fenómeno en "Casa tomada" y "Carta a una señorita en París".

Los personajes de "Casa tomada" viven, o persisten, en la "espaciosa y antigua" residencia de sus antepasados. Como ya ha visto la crítica, la idea del incesto va escondida en la narración del hermano. ${ }^{3}$ Sin embargo, lo que nadie ha señalado es la paradoja que encierra el incesto desde la situación en que vive la pareja. Más que un laberinto, la casa es el ámbito que guarda la pureza de las genealogías ("la genealogía asentada por los bisabuelos en nuestra casa"). El no venderla ni cedérsela a los "vagos y esquivos" primos, y el no haberse casado con otros, tienen como corolario el incesto mismo. A este nivel el cuento cancela la explicación etiológica (la de las causas) y afirma la estructural (la sincrónica). Que el deseo incestuoso haya sido racionalizado y proyectado hacia el deber de no casarse con otros y de permanecer en ese "simple y silencioso matrimonio de hermanos", no es lo más determinante. El cuento se sitúa por encima de cualquier dato biográfico, dándole a los pocos que cita un carácter ambiguo y hasta un poco siniestro. Cuando el hermano dice que Irene "rechazó dos pretendientes sin mayor motivo", el lector debe regresar al incesto como la única posible (necescria) explicación (las demás resultan, como diría Borges, infinitas). Lo mismo ocurre con la frase del hermano, "a mí se me murió María Esther", la cual también puede esconder innumerables causas.

El incesto se establece como la única zona de lucidez a través de la paradoja mencionada anteriormente, paradoja que resuelve la ambigüedad de: "A veces llegamos a creer que eta ella [la casa] la que no nos dejó casarnos" (Bestiario, p. 9).

El deber incestuoso impuesto por la casa sostenedora de las genealogías tendría que consumarse por medio de la descendencia, la de los hijos del incesto. Pero la paradoja se afirma de nuevo, el "simple $y$ silencioso matrimonio de hermanos" no procrea, La familia conservará su pureza, no se mezclará con otras sangres e intenciones a costo de concluir con la pareja actual. De aquí que la mayor obsesión sea la de procrear, desviada hacia el empeño de crear y contemplar toda una serie de formas para cubrir con ellas la ausencia del descendiente: "A veces tejía un chaleco y después lo destejía en un momento porque algo no le agradaba; era gracioso ver en la canastilla el montón de lana encrespada resistiéndose a perder su forma de algunas horas" (Bestiario,

3 La posibilidad del incesto es señalada por Gyurko (quien la recoge de otros críticos) en el articulo mencionado más atribạ. 
p. 10). La actividad de tejer no sólo es gratuita sino insuficiente, ya que la forma creada carece de la (en este caso) definitiva corporeidad de la criatura. Su tercer característica sería la de estar minada por el sentimiento de culpabilidad, presente en el acto de destejer mismo (análogo al asesinato) y en la destreza algo sádica de la siguiente oración: "Mostraba [Irene] una destreza maravillosa y a mí se me iban las horas viéndole las manos como erizos plateados, agujas yendo y viniendo $y$ una o dos canastillas en el suelo donde se agitaban constantemente los ovillos" (Bestiario, p. 11). La obsesión por la forma también se manifiesta en lo diminuto y geométrico:

-fíjate este punto que se me ha ocurrido. ¿No da un dibujo de trébol?

Un rato después era yo el que le ponía ante los ojos un cuadradito de papel para que viese el mérito de algún sello de Eupen y Malmédy. (Bestiario, pp. 15-16).

El patético aburrimiento no es lo único que explica este pasaje.

"Casa tomada" dramatiza la culpa que la situación paradisíaca trata de ocultar; el cuento es la pesadilla del Paraíso.4 En ambos casos el incesto es necesario, pero la conciencia que lo descubre en el paraíso lo hace retroactivamente, mientras que en "Casa tomada" la necesidad y la prohibición se dan simultáneamente. Nacer de nuevo como pareja, no como hermano y hermana sino como la pareja original (hermanos y esposos sin padres), es el sueño hecho pesadilla en el cuento.

Irónicamente, ya cercano el Final, la pareja logra un grado de intimidad corporal que le fue vedado en la casa: "Como me quedaba el reloj pulsera, vi que eran las once de la noche. Rodcé con mi brazo la cintura de Irene (yo creo que ella estaba llorando) y salimos así a la calle" (Bestiario, p. 18).

Pero librarse de la tiranía de las generaciones y consultar el reloj no señalan el ingreso en el tiempo exterior y social, sino la colocación de la pareja dentro del tiempo circular-mítico. Ser las once de la noche equivale entonces a ser la oncena bora, hora de la tiltima pareja que

- Difiero de Gyurko cuando dice: "The couple have been ignominiously driven out of their womblike paradise" (p. 555), y también con lo siguiente: "The timeless, semiconscious existence that brother and sister have led now cedes to a forced confrontation with the realities of the outside world and with the exigencies of chronological time" (p. 554). Su versión de Cortázar como "realista" (ver p. 550) me parece situar a Cortázar todaria dentro de la temática existencialista. 
dejará de existir en pos de la otra, la original, más allá de las doce, cuando los mitos se reanuden a partir de un nuevo comienzo.

No ver esta circularidad significa leer el cuento a un nivel limitadamente socio-sicológico. Limitado por cóartar el desarrollo más expansivo del cuento: el que, partiendo de las zonas de la subjetividad enajenada, termina por incluir en las coordenadas de su texto los más antiguos mitos y dilemas sostenidos y aplazados por el hombre.

En "Carta a una señorita en Paris", el departamento de la calle Suipacha encierra un orden tan potenciado, $\tan$ significado, como el de la casa del Paraíso hecho pesadilla. De nuevo es inútil establecer la cadena causal entre el trastorno psíquico y sus posibles fuentes, de nuevo el área de lucidez es el presente $y$ sus configuraciones esclarecedoras. La biografía ya no importa, sino como hipótesis confusa, substituida por el minucioso juego de telaciones de la carta. Esta no logra explicar la causa del suicidio, en cuanto vomitar conejitos (que como toda causa, es consecuencia también) sólo remite a los más oscuros datos biográficos, con las otras vidas que éstos. incluyen $y$ excluyen. Es necesario hacer hincapié en la presencia o ausencia de otras vidas por ser éste el núcleo alrededor del cual giran la carta y la conciencia enajenada de quien la escribe.

Desde el comienzo la carta se refiere al departamento $\mathrm{y}$ al "orden cerrado, construido hasta en las más finas mallas del aire". Los muebles, libros y demás objetos del departamento forman parte de un "juego de relaciones", y adquieren sentido sólo "como una reiteración visible" del alma de la ausente propietaria. $O$ sea, las cosas infieren la totalidad cuya voluntad confirman. Más tarde, abrumado por la proliferación de los conejitos, el anónimo personaje piensa en su vida, víctima de las cosas (coloquialismo en este caso fatalmente literal), de las cosas fuera de control, sin ninguna relación capaz de ordenarlas: "No es nominalismo, no es magia, solamente que las cosas no se pueden variar así de pronto, a veces las cosas viran brutalmente y cuando usted esperaba la bofetada a la derecha-. Así Andrée, o de otro modo, pero siempre así" (Bestiario, pp. 28-29).

$Y$ si los objetos del departamento son la "reiteración visible" del alma de Andrée, supeditándose a su lejana voluntad, la existencia de cada conejito y su crecimiento reducen el tiempo a la sucesión nominalista que se niega a la voluntad totalizante: "Un mes distancia tanto; un mes es tamaño, largos pelos, saltos, ojos salvajes, diferencia absoluta" (Bestiario, p. 24). Para contrastar este sentimiento el personaje insiste con fascinación en imaginar una conciencia cuyo mundo puedạ ser 
reducido a la oración que reúna sus datos esenciales: "Su menuda conciencia debia estarle revelando hechos importantes: que la vida es un movimiento hacia arriba con un click final, y que es también un cielo bajo, blanco, envolvente y oliendo a lavanda, en el fondo de un pozo tibio" (Bestiario, p. 25). Lo que llegará a ser "una presencia inajenable" en el transcurso de un mes reducido a su propio crecer es, por el momento, un diminuto círculo consciente, cómodamente aislado de los demás datos $\mathrm{y}$ hechos que se encuentran más allá del ascensor. Peto el Dios que fija los limites de esa conciencia diminuta lo hace a expensas de fragmentar el mundo y de convertirlo en el espacio de un infinito número de conciencias enajenadas las unas de las otras. El espacio es entonces percibido como una pluralidad de universos ("los rígidos cielos del primero y el segundo pisos"), regidos por un Dios que sufre de la condición de serlo.

Debo ahora citar el párrafo más importante de la carta:

Son diez. Casi todos blancos. Alzan la tibia cabeza hacia las lámparas del salón, los tres soles inmóviles de su día, ellos que aman la luz porque su noche no tiene luna ni estrellas ni faroles. Miran su triple sol y están contentos. Así es que saltan por la alfombra, a las sillas, diez manchas livianas se trasladan como una moviente constelación de una parte a otra, mientras yo quisiera verlos quietos, verlos a mis pies y quietos -un poco el sueño de todo dios, Andrée, el sueño nunca cumplido de los dioses-, no así insinuándose detrás del retrato de Miguel de Unamuno, en torno al jarrón verde claro, por la negra cavidad del escritorio, siempre menos de diez, siempre seis u ocho y yo preguntándome dónde andarán los dos que faltan, y si Sara se levantara por cualquier cosa, y la presidencia de Rivadavia que yo queria leer en la historia de López. (Bestiario, p. 28).

El carácter expansivo del cuento le permite articular lo que Beckett ha llamado con irónico cansancio "las viejas preguntas". En este sentido la textualidad del cuento significa el ser escrito a modo de conjugación de otros textos, los cuales le serán siempre simultáneos. Las viejas preguntas están siempre presentes, por encima o por debajo de lo particular y específico que se narre $y$, una vez aludidas, intervendrán para multiplicar las resonancias de la narración. Descontando otras alusiones cargadas de humor, el párrafo citado anteriormente implica, sin el menor propósito de transmitir un "mensaje", el viejo dilema de la teología 
natural trascendido por Spinoza: la dualidad Dios-Creador/Naturaleza da como resultado lógico el ver en la creación la carencia divina, prueba de la imperfección del creador. Anteriormente, la breve alusión: "Como un poema en los primeros minutos, el fruto de una noche de Idumea", atrae hacia el interior del cuento no sólo "Don du poème" de Mallarmé sino también su "Herodiade". El vértigo de lo que cabe llamar la intertextualidad (piénsese en Borges), surge al quedar enlazadas las obras: Citaté un ejemplo (el menos probable) de entre las órbitas que relacionan los tres textos. Los Reyes de Edom (Idumea) eran capaces de procrear sin necesidad de juntarse con mujer alguna. Dejo al lector que saque, si quiere, las debidas conclusiones, pero con el aviso de que una lectura cuidadosa de ambos poemas de seguro los convertiría en partes del sistema expansivo generado por "Carta à una señorita en París".

El atributo dialéctico de la intertextualidad es común a todos los textos, y esto en una civilización que a través de los siglos se ha dedicado a preservar aún los más nimios y accidentales. De entre los breves (relativo a su importancia) el Tractatus Logico-Philosopbicus de Wittgenstein se propone eliminar, a nivel del lenguaje mismo, dicha interminable dialéctica. No es de extrañarse, pues, que en su prefacio ocurra la siguiente frase que cito por la traducción inglesa: "Indeed; what I have written here makes no claim to novelty in detail, and the reason why I give no sources is that it is a matter of indifference to me whether the thoughts that I have had have been anticipated by someone else" (Tractatus Logico-Pbilosopbicus, segunda edición, Londres, 1971 ; p. 3). La frase no es arrogante, pero sí tan necesaria como la primera proposición del Tractatus: "The world is all that is the case". El proyecto de reducir el lenguaje a su esencia lógica fue suicida. Como ha dicho $\mathrm{G}$. J. Warnock (en English Pbilosopby Since 1900), el Tractatus puede haber revelado algo, pero en realidad (según sus propios enunciados) no dijo nada. La escritura del Tractatus se impone a sí misma el ser ajena a todos los demás textos, diferenciándose asi del tipo de texto que he venido analizando. Pero al final, por vía de la reducción lógicoatomista, su resultado es el mismo: no decir nada, sólo revelar.

El cuento, ha dicho Cortázar, "no indaga ni transmite un conocimiento o un mensaje" ("Del cuento breve y sus alrededores", Ulimo round, p. 42). Lo que hace es suspenderlo todo en su esfericidad. Antidoto, pero también anticipo de la muerte, suspende la diacronía al organizar un sistema de referencias que incluye otros textos, pero no yendo o remontándose hasta ellos a través del tiempo, sino revelando su virtual simultaneidad. 
La muerte se manifiesta en el accidente de escribirlo y de leerlo: "Un trozo en blanco de la página será para usted el intervalo, apenas el puente que une mi letra de ayer a mi letra de hoy... para mí este lado del papel, este lado de mi carta no continúa la calma con que yo venía escribiéndole cuando la dejé para asistir a una tarea de comisiones" (Bestiario, Pp. 31-32). La vida se hace carta para ordenarse, y el acontecer cotidiano se convierte en imágenes dentro de la lógica del texto: "El día sube, tal vez Sara se levante pronto"; imágenes que confirman la total enajenación del suicida: mientras todo sube y se levanta él caerá. Enajenación y separación que se prolongan más allá de su muerte, pues su cadáver sólo será obstáculo para la órbita ajena: "No creo que les sea difícil juntar once conejitos salpicados sobre los adoquines, tal vez ni se fijen en ellos, atareados con el otro cuerpo que conviene llevarse pronto; antes de que pasen los primeros colegiales" (Bestiario, p. 33).

\section{IV}

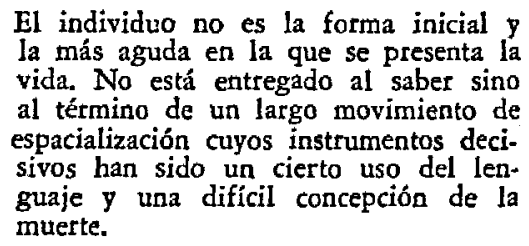

Michel Foucault; El nacimiento de la clinica.

"Cefalea" es el ejemplo más vertiginoso de la intertextualidad. Como buen bricoleur, Cortázar glosa el oscuro articulo ("admirable poema" le Ilama) de Margaret L. Tyler, "Síntomas orientadores hacia los remedios más comunes del vértigo y cefaleas" y concluye por escribir, a cierto nivel, uno de sus cuentos más borgianos. Pero antes de explicar en qué consiste esta similaridad con Borges es preciso destacar por lo menos una diferencia esencial entre ambos.

Los personajes de "Cefalea" creen en la medicina homeopática, heredera de una de las dos magias descritas por Borges en "El arte narrativo y la magia", según la conocida clasificación de Frazer. La magia imitativa establece "un vínculo inevitable entre cosas distantes" (Disctsión, p. 88). Desde la perspectiva estructuralista, su proceder es metafórico, mientras que la magia "contagiosa" opera a través de la metonimia. Para Borges el resultado de ambas es lo que importa, por cons- 
tituir "la coronación o pesadilla de lo causal, no su contradicción" (Ibid., p. 89), y por servirle de analogía para definir las mejores manifestaciones del cuento y la novela en relación con lo que él llama la "primitiva claridad de la magia". Por otra parte, sería un error acentuar lo puramente mecánico dentro del énfasis dado por Borges a lo causal. De seguro, a nivel de la diacronía, el texto concierta sus pormenores proféticos y es, en feliz frase, "un orbe autónomo de corroboraciones" (Ibid., p. 91). La autonomía del Ulysses, como la de otros textos, pretende lo imposible: la captación simultánea de todos sus componentes. La "primitiva claridad de la magia" corresponde al presente absoluto, a la transparencia regida por la lógica que excluye los incidentes de una o de muchas vidas, incorporando sólo un grupo muy reducido de ellos. La biografía se reduce a una de sus posibles figuras, la más reveladora $y$, como tal, la que más incluye, excluyendo. Pero revelar tiene aquí un significado que distingue la obra de Borges de la de Cortázar.

Acudo a un texto de Rayuela para aclarar lo dicho. Habla Ronald sobre un pasaje del Bardo:

Mira, a la hora del juicio del muerto, el rey lo enfrenta con un espejo, pero ese espejo es el Karma. La suma de los actos del muerto, te das cuenta. $\mathrm{Y}$ el muerto ve reflejarse todas sus acciones, lo bueno y lo malo, pero el reflejo no tesponde a ninguna realidad sino que es la proyección de imágenes mentales... El Rey de los muertos mira el espejo, pero lo que está haciendo en realidad es mirar en tu memoria. (capítulo 28).

El orden del presente creado en cuentos como "El Sur" es el de otro espejo que, en la misma situación de juicio final, reclama del individuo sólo el reflejo de lo necesario para plasmar su figura; juicio éste no de la memoria sino de sus "costumbres"; entendiéndose por memoria no el pasado que el personaje gutrda en sí mismo sino el que le aguarda, por no haber sido nunca de él. El destino no se revela desde la interioridad, ya que ésta no existe. El personaje (Dahlmann o Erik Lönnrot, por ejemplo) se proyecta hacia los contornos de su última verdad, hacia el resultado más amplio y potenciado de su multiplicidad.

La situación sugiere paralelos con la tragedia griega que me limitaré a tesumir basándome en la crítica reciente. En su libro $O_{n}$ Aristotle and Greek Tragedy (Oxford, 1962), John Jones contrasta la noción aristotélica de acción con ciertos hábitos modernos que situarían el origen de Ia praxis en el interior de los personajes. Dice Jones: "Ạristotle 
is assaulting the now settled habit in which we see action issuing from a solitary focus of consciousness - secret, inward, interesting - and in which the status of action must always be adjectival: action qualifies; it tells us things we want to know about the individual promoting it; the life of action is our ceaseless, animating consideration of the state of affairs 'inside' him who acts, without which action is empty and tri-' vial, an effluvium" (P. 33). La reflexión ética (en su sentido etimológico de etbos, carácter) a que conduce la tragedia parte de considerar el "carácter" de la figura central como el resultado actual y exteriorizado. de las acciones pretéritas encadenadas por el "hábito" (hexis) o inclinación. La máscara trágica une al hombre con su verdad, en ella, pero no dentro de ella, el hombre sobrepasa la naturaleza, porque la máscara impone "el lúcido aislamiento de sus rasgos esenciales" ("Its lucid isolation of essentials"; Jones, p. 45). Todo es figura, gesto $\mathrm{y}$ acción; el ser se resuelve en sus facciones ("Its being is exhausted in its features"; Jones, $\mathrm{p}, 45$ ).

La primacía de lo externo y objetivado se acentúa en la interpretación de Jean-Pierre Vernant (en "La Tragédie Grecque: problèmes d'interprétation", cuya traducción inglesa aparece en The Structuralist Controversy, Baltimore, 1970). Las figuras de la tragedia sirven para. que la polis se autoexamine $y$ el hombre interrogue su nueva capacidad de actuar según su naciente voluntad humana. Vernant señala la convergencia de la triada pasado-presente-futuro sobre un instante de la acción trágica ("Past, present and future merge in a single significant act"). La tragedia se decide a partir del acto que lo incluje todo.

La narrativa de Borges es heredada de la economía dramática de los poetas trágicos. El repetido encuentro en sus ficciones entre el personaje y su destino es un hecho tan externo, vasto e instantáneo como el de la anagnórisis trágica. El destino todavía tiene en Borges la vigencia que Cortázar le niega en Bestiario, al trasladar la enajenación de sus personajes al plano de lo patológico. Pero, como ya se ha visto, esta zona carece de orígenes en su ficción, pues la opaca interioridad a la que a veces daba acceso la narrativa del diecinueve, es absorbida por los síntomas convertidos en metáforas e imágenes que no refieren a otra cosa que no sea su propia manera de conjugarse.

"Cefalea" se narra desde el punto cero de la enajenación, desde el perpetuo presente de los signos. El "nosotros" que narra anula la subjetividad convirtiéndola en su accidente, y todo vestigio humano no es más que un término dentro de la constelación de los signos: puro sigrificante. Es imposible determinar con certeza cuántos seres van incluidos 
en el "nosotros", ya que aparte de Leonor y el Chango (quienes, provisionalmente, pertenecerían a la esfera de lo normal) la diferenciación es en extremo ambigua, limitándose a las tres polaridades: "uno de nosotros-el otro", "uno de nosotros-la otra" y "una de nosotros-el otro". Nótese que aunque existieran más de dos enfermos la diferenciación es siempre binaria, lo cual hace posible suponer que se trate sólo de dos individuos.

En apoyo de esta hipótesis señalo lo siguiente. Cada uno de los cuadros sintomatológicos lleva el nombre de la droga que lo imita (Aconitum, Phosphorus, Natrum mutriaticum, Onosmoditum, etc.) más la des. cripción de sus efectos, homólogos a los sintomas mismos según la homeopatia. Las cefaleas se hacen intelegibles al ser codificadas, creándose un lenguaje, el único posible, entre los enfermos, y entre éstos y el fenómeno en bruto de la enfermedad. El código no adjudica cada uno de los cuadros a un enfermo en particular, sólo les permite reconocerse en el otro, o reconocer al otro dentro de sí mismos o, finalmente, supeditar ambas entidades a los signos que las homologizan. Baste un ejemplo de los muchos en "Cefalea": "uno de nosotros ha debido reconocer, con qué amargo sentimiento, el avance de un cuadro Silica. Empieza en el momento mismo en que nos domina el sueño..." (Bestiario, p. 75).

El método nosológico de la medicina del dieciocho descrito por Foucault en El nacimiento de la clínica (México, 1968) ofrece paralelos esclarecedores:

Antes de ser tomada en el espesor del cuerpo, la enfermedad recibe una organización jerarquizada en familias, géneros y especies. Aparentemente no se trata más que de un "cuadto" que permite hacer sensible, al aprendizaje y a la memoria, el copioso dominio de las enfermedades... En el plano fundamental de la enfermedad, los médicos y los enfermos no están implicados de pleno derecho; son tolerados como tantas otras perturbaciones difícilmente evitables: el papel paradójico de la medicina consiste, sobre todo, en neutralizarlos, el mantener entre ellos el máximo de distancia para que la configuración ideal de la enfermedad, entre sus dos silencios, y el vacio que se abre del uno al otro, se haga forma concreta, libre, totalizada al fin en un cuadro inmóvil, simultáneo, sin espesor ni secreto donde el reconocimiento se abre por si mismo, sobre el orden de las esencias. (pp. 18-24). 
L2 situación en "Cefalea" que me interesa subrayar se resume en otra frase citada por Foucault del Traité de l'Experience de Zimmermann. Para éste la enfermedad se ajusta a "leyes inmutables", que "se descubren bien pronto, si el curso de la enfermedad no es interrumpido o perturbado por el enfermo"; "en este nivel (concluye Foucault) el individuo no era más que un elemento negativo, el accidente de la enfermedad, que, para ella y en ella, es el más extraño a su esencia". (p. 32).

Los síntomas organizados en cuadros vacían la subjetividad y eliminan sus fronteras, asimilando y neutralizando la naturaleza en bruto de la enfermedad, pero el equilibrio se deshace, porque son los signos mismos los que, al propiciar el encadenamiento de las imágenes, lo arrastran todo hacia la otra vertiente de la locura, la más aterradora, por representar la naturaleza sublevada. El punto de enlace los significantes de los cuadros homeopáticos y la presencia de las mancuspias se da a través del verbo trepar y la transformación de éste en reptar:

Empieza en el momento mismo en que nos domina el sueño, es un perder la estabilidad, un salto adentro, un vértigo que trepa por la columna vertebral hacia el interior de la cabeza; como el mismo trepar reptante (no hay otra descripción) de las pequeñas mancuspias por los postes de los corrales. (p. 75).

Es éste el núcleo mismo del haz de signos que se autogenera en pos del terror que en un principio creyó poder evitar. La fusión entre la nomenclatura de los síntomas y el desenfreno animal se manifiesta en el nombre de los últimos dos cuadros de la progresión sintomatológica (Apis y Crotalus-cascovella). El último marca el cierre de las transformaciones, más allá de él no puede haber más signos dilatorios porque lo que él comunica es la pura equivalencia: "uno de nosotros repite la mención, nos alegra comprender tan bien el latín, crótalo cascabel, pero es decir lo mismo porque cascabel equivale a crótalo" (Bestiario, p. 89). Y esta aterradora equivalencia sugiere otra: dentro de la entidad "uno de nosotros" lo uno equivale a lo otro; el yo es tít en el imperio de los signos.

Ya dije que "Cefalea" era el cuento más borgiano de Cortázar, y lo es sólo por narrar, como "Tlön, Uqbar, Orbis Tertius", la Utopia hecha pesadilla. Foucault, quien ha relacionado la escritura de Borges con el concepto de beterotopía, provee las claves de esta comparación al describir la relación entre la lectura médica y la filosofía del lenguaje de Condillac. "Por último, dice Foucault, en el horizonte de la 
experiencia clínica, se dibuja la posibilidad de una lectura exhaustiva, sin oscuridad ni residuo: parà el médico cuyos conocimientos fueran llerados 'al más alto grado de perfección, todos los síntomas podrian convertirse en signos': todas las manifestaciones patológicas hablarian un lenguaje claro y ordenado. Se estaría por último al mismo nivel que esta forma serena y realizada del conocimiento científico de la cual habla Condillac, y que es 'lengua bien hecha" (El nacimiento de la clinica, pp. 137-38).

¿Y qué hace la locura en "Cefalea", al codificar los términos de su visión, sino minar la confianza de esa otra presencia que tan racionalmente y desde afuera la condena al silencio?

Bennington College.

\author{
EduARDo G. GonZÁlez
}

